\title{
Insights on the relationship between decision-making style and personality in software engineering
}

\author{
Fabiana Mendes a,b,*, Emília Mendes c ${ }^{\text {, Norsaremah Salleh }}{ }^{\mathrm{d}}$, Markku Oivo ${ }^{\text {a }}$ \\ ${ }^{a}$ Faculty of Information Technology and Electrical Engineering, University of Oulu, P.O. Box 3000, 90014, Finland \\ ${ }^{\mathrm{b}}$ Faculty UnB Gama. University of Brasília. St. Leste Projeção A - Gama Leste, Brasília -DF, 72444-240, Brazil \\ ${ }^{\mathrm{c}}$ Department of Computer Science, Blekinge Institute of Technology, Karlskrona, Sweden \\ ${ }^{\mathrm{d}}$ Department of Computer Science, IIUM, P.O. Box 10, 50728 Kuala Lumpur, Malaysia
}

\section{A R T I C L E I N F O}

\section{Keywords:}

Decision-making style

Personality

Software engineering

\begin{abstract}
A B S T R A C T
Context: Software development involves many activities, and decision making is an essential one. Various factors can impact a decision-making process, and by understanding such factors, one can improve the process. Since people are the ones making decisions, some human-related aspects are amongst those influencing factors. One such aspect is the decision maker's personality.

Objective: This research investigates the relationship between decision-making style and personality within the context of software project development.

Method: We conducted a survey in a population of Brazilian software engineers to gather data on their personality and decision-making style.

Results: Data from 63 participants was gathered and resulted in the identification of seven statistically significant correlations between decision-making style and personality (personality factor and personality facets). Furthermore, we built a regression model in which decision-making style (DMS) was the response variable and personality factors the independent variables. The backward elimination procedure selected only agreeableness to explain $4.2 \%$ of DMS variation. The model accuracy was evaluated and deemed good enough. Regarding the moderation effect of demographic variables (age, educational level, experience, and role) on the relationship between DMS and Agreeableness, the analysis showed that only software engineers' role has such effect.

Conclusion: This paper contributes toward understanding the relationship between DMS and personality. Results show that the personality variable agreeableness can explain the variation in decision-making style. Furthermore, someone's role in a software development project can impact the strength of the relationship between DMS and agreeableness.
\end{abstract}

\section{Introduction}

Professional practice is a process of problem-solving, which involves making decisions [1] and this is not different in software development, as it can be conceived as a set of decisions [2].

A poor or suboptimal decision can impact software development. For example, a manager's poor decision can lead to a software project's failure [3]. A requirements engineer's wrong decision about the inclusion of a requirement can lead to an incomplete software requirements list, and a consequent software project failure [4]. A suboptimal decision on software architecture can impact the software quality [5]. The choice of old technology can lead to software with a short life span [6].
There are, indeed, many potential reasons for a poor or suboptimal decision, e.g., time pressure, communication, and an incorrect approach [7]. Many studies propose a way to improve decision-making. For example, Dyba et al. [8], Dorst [9] and Razavian et al. [10] highlight the importance of reflection to improve decision-making. Lytra and Zdun [11] proposes an approach to improve the software architecture decision-making. Vroom and Yetton [12] highlight the amount of stakeholder participation in the decision-making process.

Malavolta et al. [13] state that the decision-making process is not only data-driven but it is also people-driven. Because of the importance of human aspects in decision-making, it is also important to explore the human issues behind a poor decision. Razavian et al. [10] list

\footnotetext{
* Corresponding author at: Faculty UnB Gama. University of Brasília. St. Leste Projeção A - Gama Leste, Brasília -DF, 72444-240, Brazil.

E-mail addresses: fabiana.mendes@oulu.fi, fabianamendes@unb.br (F. Mendes), emilia.mendes@bth.se (E. Mendes), norsaremah@iium.edu.my (N. Salleh), markku.oivo@oulu.fi (M. Oivo).
} 
several human issues behind a poor decision, such as cognitive bias, which can be caused, amongst other reasons, by social attributes or even some specific personality traits. In this context, the reflection plays an important role in overcoming such issues; for example, decision reasoning could help information gathering, problem identification, and solution selection [10].

Abatecola et al. [14] conducted a literature review in which they selected 29 studies from the Business and Management fields discussing the relationship between personality and decision-making. As a result, the paper related personality traits to the management outcomes such as decision-making speed, leadership effectiveness, and information acquisition.

Despite the interest in other fields in characterizing the relationship between personality and decision-making, a recent systematic literature review conducted by Mendes et al. [15] showed a gap in studies in Software Engineering on the abovementioned relationship.

Mendes et al. [15] identified 30 different decision-making aspects relating to personality, and decision-making style (DMS) is among them. Vroom and Yetton [16] define DMS as the level of stakeholder participation in the decision-making process; in other words, a DMS indicates how much the decision-maker allows others to participate in the decision-making process.

In this context, McAvoy and Butler [17] highlighted that the lack of empowerment in the decision-making process could lead to a failure in agile software development projects, which could be interpreted that a more participative DMS is needed in order to gain success in an agile software project.

Therefore, this work's main motivation is to explore this gap pointed by Mendes et al. [15], i.e., to investigate the relationship between decision-making style and personality within a software engineering context. This would lead us to address questions such as: How can a software development organization improve the decision-making process by considering decision-makers' personalities? What are the personality factors that interfere with such a process?

Our main research goal is to understand the relationship between personality and decision-making style (DMS) by (1) investigating if such a relationship exists, (2) verifying if personality factors can be used to explain the variation in DMS, and (3) identifying if demographic variables moderate the relationship between DMS and personality.

In order to achieve this goal, we performed an exploratory study [18] to assess the relationship between decision-making style and personality through a survey investigation. Our population consisted of software engineers, and the collected data included participants' personality factors (independent variables) and decision-making style (dependent variable).

The contributions of this paper are as follows:

- Characterization of the relationship between decision-making style and personality.

- Identification of personality factors that explain the variation in decision-making style.

- Identification of demographic factors that interfere with the relationship between decision-making style and personality.

The remaining sections are organized as follows. Section 2 presents the works related to the research reported herein. Section 3 shows details about the research methodology, including the survey procedures, variables, and how the data was analyzed. Section 4 describes the results and Section 5 discusses them. Section 6 presents the threats to the validity of the results and, finally, Section 7 presents the conclusions, including the future works related to this research.

\section{Related work}

This section presents previous research that relates to the work detailed herein, arranged into three sub-sections. Section 2.1 describes concepts and related work on decision-making and Section 2.2 does so in relation to personality. Finally, Section 2.3 presents studies that discuss the relationship between decision-making and personality.

\subsection{Decision-making}

A decision represents a choice made out of some alternatives and implies, in many cases, a commitment of resources $[19,20]$. In turn, a decision-making process comprises a set of steps leading to a decision. An example of such process is represented by the following five main steps: (1) identify the problem; (2) generate potential solutions; (3) choose a solution amongst the available alternatives; (4) implement the solution; (5) evaluate the effectiveness of the implemented solution [7].

Decision is an important topic in software engineering. Burge et al. [2] even define that software development could be conceived as a set of decisions. McAvoy and Butler [17] highlight the interconnection among the set of decisions, which implies that one decision leads to and impacts upon other decision(s) in the same software project development.

There are many software engineering studies related to decisionmaking, as detailed next. The systematic literature review by Cunha et al. [21] investigated how software project managers make their decisions. They identified 27 studies comprising eight main topics. The topic with the highest number of studies was agile development practices. The studies under this topic discuss the challenges of shared decision-making on agile teams [22], map agile practices to the decision-making process [23], discuss empowerment and group consensus in agile teams, and explore the negative impact of agile practices on decision-making $[17,24]$.

Colomo-Palacios et al. [25] is one of the studies cited in Cunha et al.'s [21] literature review, and it elaborates upon the impact of emotions in IT organizations' hard decisions. Although emotions are related to neuroticism (a personality factor), this paper does not discuss them from this perspective. Medina and Francis [26] highlight that a good project manager should involve people in the decisions, and Rose et al. [27] state the importance of having the entire team engaged in the decision-making.

Another software engineering literature review investigated environmental factors that impact individual decision-making [28]. The authors identified 40 papers, from which they extracted 237 factors. They aggregated these factors and proposed a taxonomy of environmental factors affecting individual decision-making in software projects.

Concerning the decision-making process, Malavolta et al. [13] state that group decision-making is the best choice, i.e., the more people participating in the process, the better it is. Many authors highlight the importance of collaborative decision-making on producing accurate and complete architecture related decisions [29,30].

However, Vroom and Yetton [16] have another point of view; according to them, the amount of stakeholders' participation in decisionmaking depends on the problem's attributes. In this context, a problem is a situation that needs a decision, and a problem attribute is a characteristic that influences the decision effectiveness.

Vroom and Yetton [16] propose a definition decision-making style (DMS) that, according to them, represents how much the leader decision-maker allows other stakeholders to participate in the decisionmaking process. The concept was defined considering a model that consists of two perspectives: normative and descriptive [16]. The normative model helps an organization improve its decision-making process. It aims to assess the problem's attributes and suggest the optimal DMS for that situation.

On the other side, the descriptive model aims to characterize one's decision-making style considering others' participation in the process. The assessment comprises 30 problems derived from interviews conducted on different industry segments (chemical, energy, among others). Each problem presents a scenario that combines different problem attributes, and the respondent needs to choose amongst five alternatives that vary according to the stakeholders' participation in the decision-making process. Fig. 1 illustrates all the styles defined by the authors. 

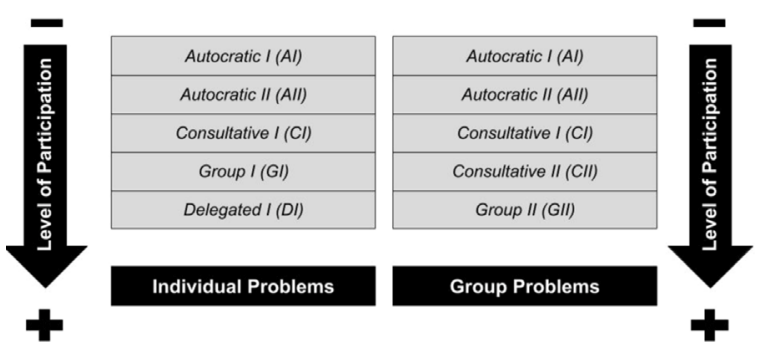

Fig. 1. Decision-Making styles [16].

Fig. 1 shows that a problem can be classified according to its applicability. If a problem affects only one person, it is classified into individual problems and if it affects more than one person, into group problems. The investigation presented herein focuses on the group problems because we understand that decisions made in software development projects usually affect more than one person. Since this is the instrument chosen to measure DMS, more details about the descriptive model, particularly its assessment items and score computing formula, are presented in Section 3.4. The following section presents concepts and discusses work related to personality.

\subsection{Personality}

The word personality is originated from the Latin word persona, which implies the "outward appearance or the face we display to people around us" [31].

Personality is a term commonly used to describe how someone is; for example, you can say that someone has a good personality meaning that you like that person, or that someone has no personality meaning that you think that person is boring [32]. There is, however, a distinction between how the general population uses the term personality and how psychologists use it.

Usually, the general population employs the term personality to describe the specific behavior of a specific person; however, psychologists use it to describe what everyone's personality consists of [33].

Bergner [34] discusses many personality definitions and states one that matches very closely the meaning we employed within the context of this research. According to Bergner, individual personality is regarded as a set of enduring characteristics (traits and styles) that someone exhibits, representing his/her uniqueness. Those characteristics are influenced by one's disposition. Endurance is related to the recurring nature of the characteristics across time, and disposition represents a person's tendency to exhibit such characteristics across different situations, usually explained by the person's internal process.

The Five-Factor Model (FFM) integrates all personality traits into five main dimensions. These dimensions (or traits) are neuroticism, extraversion, openness, agreeableness, and conscientiousness.

Extraversion and agreeableness are factors related to one's interpersonal abilities [32] However, extraversion focuses on one's sociability, whereas agreeableness focuses on one's tendency to be cooperative and compassionate toward others [35].

Conscientiousness is a factor related to how controlled and disciplined someone is [36]. Neuroticism is also called emotional stability, and it expresses how someone deals with his/her own emotions [35]. Finally, openness is related to creativity and how someone experiences life [32]. The five factors and some adjectives for each one are presented as follows [31]:

- Agreeableness: good-natured, soft-hearted

- Conscientiousness: hardworking, organized

- Extraversion: sociable, talkative, fun-loving

- Neuroticism: worried, insecure, nervous

\section{- Openness: original, independent, creative}

There are many scales associated with the FFM. For example, California Personality Inventory (CPI), Personality Assessment Inventory, 16 Personality Factors (16 PF) [37], NEO Personality Inventory (NEOPI) and its versions [38].

The IPIP-NEO is a questionnaire created by Johnson [39]. The questionnaire's items were derived from the NEO-PI set of items. It focuses on the five main personality factors which are detailed into personality facets (six facets per factor), as shown in Table 1.

Table 1

Personality factors and their facets.

\begin{tabular}{l}
\hline A - Agreeableness \\
\hline A1 - Trust \\
A2 - Morality \\
A3 - Altruism \\
A4 - Cooperation \\
A5 - Modesty \\
A6 - Sympathy \\
\hline C - Conscientiousness \\
\hline C1 - Self-Efficacy \\
C2 - Orderliness \\
C3 - Dutifulness \\
C4 - Achievement-Striving \\
C5 - Self-Discipline \\
C6 - Cautiousness \\
\hline E - Extraversion \\
\hline E1 - Friendliness \\
E2 - Gregariousness \\
E3 - Assertiveness \\
E4 - Activity Level \\
E5 - Excitement-seeking \\
E6 - Cheerfulness
\end{tabular}

\begin{tabular}{l}
\hline $\mathbf{N}$ - Neuroticism \\
\hline N1 - Anxiety \\
N2 - Anger \\
N3 - Depression \\
N4 - Self-Conscientiousness \\
N5 - Immoderation \\
N6 - Vulnerability \\
\hline O - Openness \\
\hline O1 - Imagination \\
O2 - Artistic Interests \\
O3 - Emotionality \\
O4 - Adventurousness \\
O5 - Intellect \\
O6 - Liberalism \\
\hline
\end{tabular}

The personality facets aim to detail the characteristics related to each personality factor. Therefore, the use of facets can provide much more detailed information about someone's individual differences.

Although the scientific study of personality started in 1852 [40], the first publication in the software engineering field about personality only appeared in 1972 [41]. The mapping study conducted by Cruz et al. [41] identified 90 studies from 1972 to 2010. Considering the authors' classification by topics, the main interest in software engineering research is the impact of personality on the software development team (pair programming, team effectiveness, and sof process allocation) and on education [41]. Despite a large number of included studies and the diversity of topics, none of them discuss the relationship between personality and decision-making.

Cruz et al. [41] also present the most used personality models in software engineering. Most of the studies employed the MBTI (MyersBriggs Type Indicator) to assess personality (48\%; 36 studies), followed by FFM (19\%; 14 studies) and KTS (Kersey Temperament Sorter, 9\%; seven studies). This finding is similar to that presented in Barroso et al.'s (2017) literature review, which notes that MBTI and FFM are the most popular personality assessment instruments used in software-engineering studies.

Barroso et al.'s literature review [42] investigates the influence of human personality on software engineering professionals, and it includes 21 studies published from 2003 to 2016 . They sought evidence of whether personality influences the "activities performed by software engineering professionals". The authors found evidence of personality influence in some activities, such as software testing [43]. Some of the included papers bring a characterization of personality types for software engineers $[44,45]$. However, none of the included studies in this literature review discusses the relationship between personality and decision-making. The following section discusses studies about the relationship between decision-making and personality carried out on other fields of science rather than Software Engineering. 


\subsection{Decision-making style and personality relationship}

The relationship between decision-making and personality has been extensively studied by other science fields, especially Management [15]. In total, Mendes et al. included 15 studies in their systematic literature review from where they identified 28 different personality aspects, 30 decision-making aspects, and 75 reported relationships between them. However, none of the included studies were conducted in the Software Engineering context.

Among the identified decision-making aspects identified by Mendes et al. [15] is DMS, which contains three studies reporting six relationships. Müller et al. [46] discuss the relationship between DMS and personality differences. They employed a mixed-method approach starting with an interview and grounded theory to analyze the collected data. The theories were validated through a survey investigation. The DMS variables were classified into two categories: DMS differences and DMS per si. Among many conclusions of the study, the authors found out that differences in the DMS can be attributed to differences in the individuals' personality.

Hunt et al. [47] investigated the relationship between cognitive style and decision-making. The cognitive style is measured by employing MBTI, a personality model. During the experiment, the participants received a narrative case representing stages of the decision process with a set of possible actions. The respondent should choose one of the options. Considering the responses, the participant's DMS was characterized between three available options: analytic, intuitive, or mixed. Then, the participant DMS was compared with the MBTI results. By the end, the authors indicated the percentage of respondents with certain personality traits with a certain DMS (analytic, intuitive, or mixed). This same relationship is also discussed by Klein [48], which highlights that intuition is related to experience and impacts decision-making.

The study conducted by Selart [49] employs the same DMS concept and instrument used in our research. However, Selart [49] characterizes an individual's DMS through only six cases, instead of 30, which is the complete instrument proposed by Vroom and Yetton [12]. Selart [49] seeks the relationship between locus of control and two DMS (participative and group consultive). The study found a positive relationship between a participative DMS and locus of control and a positive relationship between the same personality trait and group consultive DMS.

The research detailed in this paper goes beyond Selart's one. We investigated all the possible DMS and all five FFM's personality traits rather than only locus of control. Furthermore, we investigated the phenomenon in the Software Development context. The following section presents details about the research methodology we employed.

\section{Research methodology}

This research's main goal is to understand the relationship between personality and decision-making style. This goal is reached by answering the research questions presented in Table 2.

These goals were reached by employing survey research [50,51]. The following subsections detail the survey design, as follows: Section 3.1 characterizes the survey population and sample, Section 3.2 describes the data collection, Section 3.3 provides details about the variables employed herein, Section 3.4 presents the instrument used to collect data and Section 3.5 documents the techniques employed to analyze them.

\subsection{Population and sample}

In total, 344 people were contacted, out of which 138 agreed to participate (40.12\%); however, only 63 participants completed all three parts of the questionnaire. Most respondents are male (72.59\%), with ages ranging between 26 to 35 years $(57.84 \%)$. The most common role is technical (50\%); the most frequent education level is a bachelor's degree $(62.75 \%)$; and back when the survey data were gathered, most participants had between two and five years of experience in Software Engineering related activities (35.29\%). Details on the sample characterization are presented in Appendix A.

This survey aimed at professionals who are involved in the decisionmaking process in the software engineering context. We defined three categories of such professionals, which are presented next:

- Business-related: people who know about the business and contribute to requirements or any other business knowledge needed to understand the software characteristics.

- Management-related: people who perform any task related to software project management.

- Technical-related: people who perform any task necessary to develop the software directly, such as requirements engineers, software architects, developers, and testers.

These categories were motivated by the work from Schwaber and Sutherland [52], who define teams as being composed of team leaders (management-related professionals), team members (technical-related professionals), and product owners (business-related professionals). From our perspective, these three categories are concise and summarize the main roles involved in software development, which is why we chose them.

The criteria to select the survey population are summarized following.

- the participant should be involved in the decision-making process on software engineering context;

- the participant should be actively engaged professionally at least in one or more of the three defined roles (business, management, or technical).

All the participants were the first author's acquaintances; therefore, we used a non-probabilistic, convenience sample. They were contacted via email or other online messaging tools (such as Facebook and LinkedIn messengers). Participation in the survey was voluntary, and only the respondents who agreed to participate received a link to the survey's data collection instrument (an online questionnaire). We also executed snowballing by asking some people to contact others who might also be willing to participate in the study (non-probabilistic, snowballing).

\subsection{Procedure}

This survey was executed considering three main phases: planning, recruitment, and data collection. The survey planning was performed between March 2018 and June 2018. During this phase, we defined the survey goals, variables, and the instruments to collect information for each variable. We also performed a survey pilot to verify: (a) the estimated time reported to complete the survey; (b) the clarity and understandability of the questionnaires; (c) the arrangement of the questionnaires and the decision-making style cases; and (d) any opportunities for improvement of the survey's execution process.

The recruitment phase happened during June 2018. We sent out a message with the research goal, and other details related to the survey, to 344 people. The message also asked for those contacted to suggest other people who could participate in the survey. We sent an email with the questionnaire link only for those who agreed to participate in the survey.

The data collection phase started when we sent the questionnaire's link to the participants. We also sent three follow-up reminders to increase the dataset size. It was executed from July to September 2018.

In order to provide feedback to the survey participants, we created a report for every person who wanted and completed the survey. The report briefly explained the theory behind the questions and the participant's score for the five personality facets and decision-making style. 
Table 2

Research questions and their motivation.

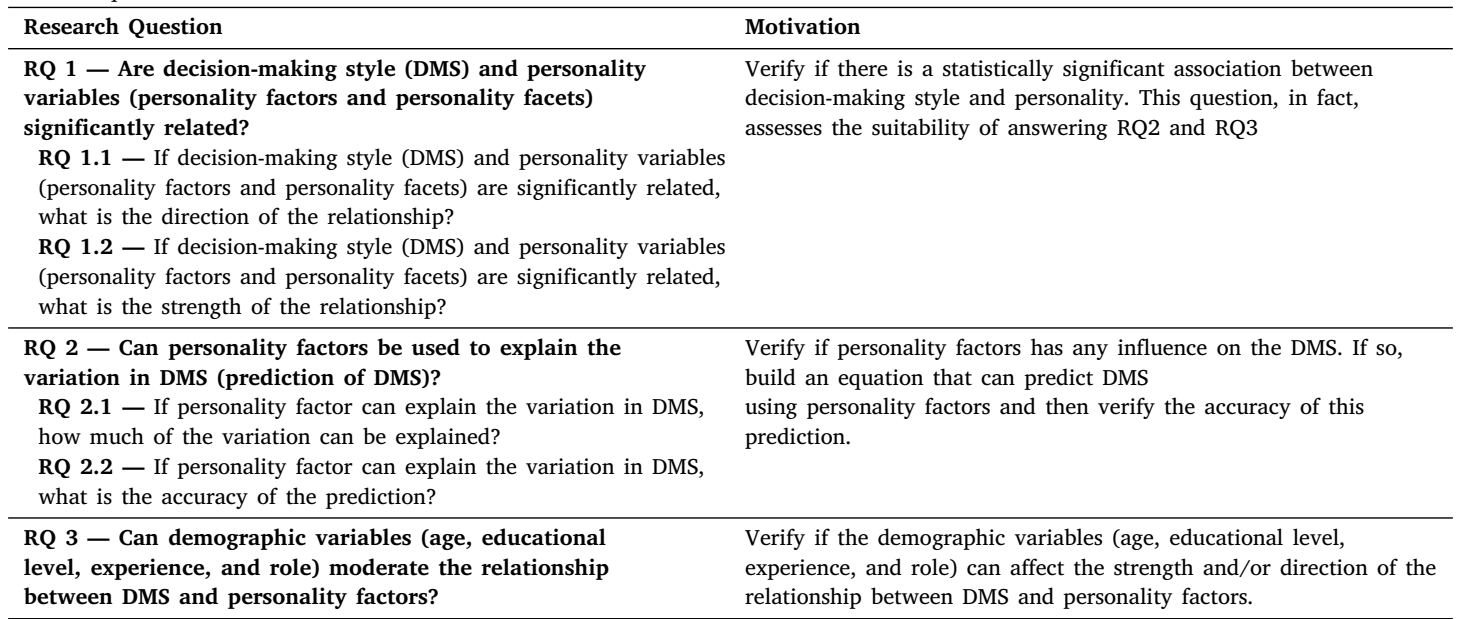

We received feedback from 15 out of the 61 reports we sent, with their experience in answering the survey. Some of them stated that they had never thought about how they decide before participating in the survey. Others said that the survey helped them think about some factors that can influence their decisions. Some confirmed that the report describes their decision-making and personality characteristics correctly.

\subsection{Variables}

Fig. 2 shows the variables for which we collected data about the relationship between personality and decision-making style in the context of Software Engineering. Regarding the scale, personality and decisionmaking style are measured on an interval (or continuous) scale. Age, educational level, and experience are measured on an ordinal scale; and role in a nominal scale [50]

In this survey, the dependent variable is decision-making style. The independent variables are those associated with personality (i.e., personality factors and personality facets). The moderation factors are the demographic variables (i.e., age, role, educational level, and experience). An overview of the data collected for these variables is presented in Appendix A.

\subsection{Data collection instrument}

The instrument used in the survey for gathering data is a questionnaire containing three parts: (1) personal information, (2) personality data, and (3) decision-making style. The questionnaire was self-administered using Webropol. ${ }^{1}$ All the questions are closed-ended, which means that the participant should choose one of the listed alternatives.

The personal information part aims to characterize participants' demographics. Therefore, it includes questions about gender, age, education level, experience, and role in the project. This first part has six questions in total, and the estimated time to complete ranges from 5 to $10 \mathrm{~min}$.

The personality assessment part uses a questionnaire proposed by Johnson [39]. It focuses on the five factors, and it also defines six facets for each factor, as shown in Table 1

We chose the IPIP-NEO questionnaire because it has been used in many studies [53-55] and because it is a public domain, free for use and available on the Web. ${ }^{2}$ It has two versions; one contains 300 items,

1 http://w3.webropol.com.

2 http://www.personal.psu.edu/ j5j/IPIP/.

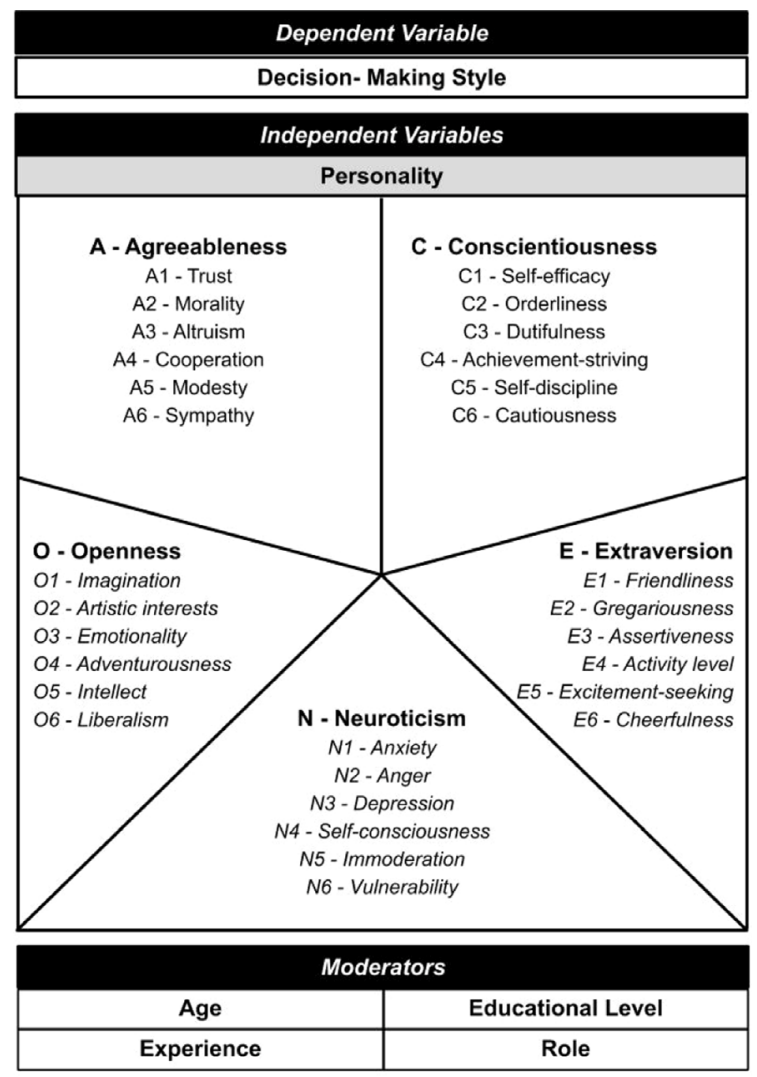

Fig. 2. Survey variables.

while the other has 120 . We decided to employ the latter because, despite the former's superior reliability, by comparison, the shorter version can be completed more quickly (between 10 to $20 \mathrm{~min}$ ).

Each item in the personality questionnaire is related to one personality factor and one personality facet simultaneously; moreover, each item can be + or -keyed. A +keyed item adds value from 1 (very inaccurate) to 5 (very accurate) points to the personality score (personality factor and personality facet), and a -keyed the score attribution is inverted, ${ }^{3}$ as shown in Table 3.

${ }^{3}$ https://ipip.ori.org/newScoringInstructions.htm. 
Table 3

Score calculation for personality variables.

\begin{tabular}{lcc}
\hline Chosen alternative & +keyed & -keyed \\
\hline Very accurate & 5 & 1 \\
Moderately accurate & 4 & 2 \\
Neither inaccurate & 3 & 3 \\
nor accurate & & \\
Moderately inaccurate & 2 & 4 \\
Very inaccurate & 1 & 5 \\
\hline
\end{tabular}

In Table 3, considering that the total number of questionnaire items per factor is 24 , each personality factor's theoretical score is between 24 and 120 . Since the total number of questionnaire items per facet is 4 , each personality facet's theoretical score is between 4 and 20).

Finally, the decision-making style part assesses how much the decision-maker leader allows other people to participate in the decision process. The employed questionnaire contains 30 problems to assess the decision-making style [56] and a scale to compute the level of participation for each problem [57]. The scenarios are real problems collected through many interviews at companies from different segments (such as the chemical industry, energy industry). The problem set considers a combination of different problems attributes such as the availability of information, problem structure, and chances of the decision be accepted through organization [16].

For each problem, the respondent needs to choose one of five alternatives that are the same for all of them. The five alternatives are shown in Table 4, along with the added score if the alternative is chosen.

Since the questionnaire has 30 problems, each participant can have a decision-making style score between 0 and 300 (DM Style.score $=$ $\sum_{n=1}^{30}$ chosen.alternative.score). Higher scores indicate a more participative decision-making style and lower scores less participative style [12]. A sample of the DMS questionnaire can be found at https://tinyurl. com/ys5u788r. The estimated time for completing the decision-making style assessment is from 1.5 to $3 \mathrm{~h}$ ( 3 to 6 min per problem). This is rather long and motivated us to divide the data collection into four parts, as presented following:

- Part 1: Personal information (6 questions) and personality questionnaires (120 items)

- Part 2: Decision-making style problems (12 cases)

- Part 3: Decision-making style problems (9 cases)

- Part 4: Decision-making style problems (9 cases)

The participant initially received the link to Part 1 . After concluding each part, the respondent received the link to the next part until all of them were completed.

\subsection{Data analysis}

This research has three main research questions (see Table 2), and for each one, we defined a different statistical approach, which is presented next. In all the analysis conducted in this study, a test was considered statistically valid if $p \leq 0.05$.

The first research question (RQ 01) relates to measuring the strength of association between decision-making style and personality variables (personality factor and personality facets), and checking whether there are any significant associations. We employed a statistical technique called correlation analysis to measure the association and flag significant relationships (RQ 1.1) and to quantify the strength of the significant relationships (RQ 1.2). The related result is presented in Section 4.1.

The scale of decision-making style and personality variable is continuous; however, some variables are not normally distributed, and some of the relationships are non-linear. Hence, we employed a nonparametric statistical test - Spearman's correlation test, because it is a technique that does not make any assumptions about variables' distributions and relationships.

The second research question aimed to verify whether personality factors can predict the variation in the decision-making style; if so, then we build a regression model by means of a regression analysis that best presents the amount of explained variation using personality factors as predictors (RQ 2.1). The model's prediction accuracy was also assessed (RQ 2.2).

In order to answer RQ 2.1, we employed a linear regression approach with backward elimination of variables. Also, crossvalidation was employed further to check the model's accuracy (RQ 2.2) and to support our results. The selected model and its accuracy is shown in Section 4.2.

According to Babyak [58], for each response variable in a model, we would need less than $S / 10$ predictor variables to include in this model. Considering the number of personality facets (30), we would need at least a sample size equal to 300 data points to include all the personality facets as predictor variables. Therefore, due to our sample size (63 data points), we chose to run the regression analysis considering only the personality factors.

The cross-validation approach was used to check the accuracy of the prediction model [59] and to compare the predicted model to the median model. We randomly split our dataset into five size. Regarding the regression with DMS as a dependent variable, we split this dataset into five-folds, as shown in Fig. 3.

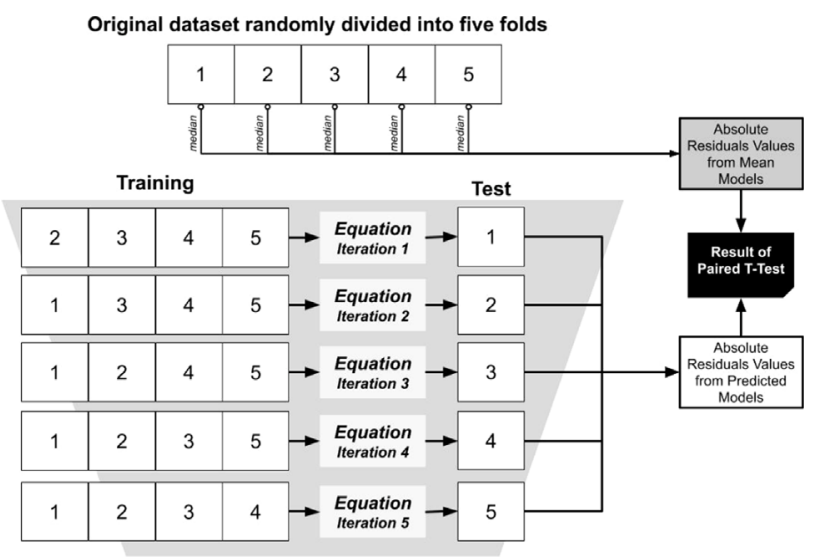

Fig. 3. Cross-validation procedure.

Note in Fig. 3 that the folds were used to build the mean model and the predicted model. The mean model was created by filling each dataset entry in the fold with the fold's mean value.

The predicted model was created as follows: one fold was reserved for testing and the remaining ones for training at each iteration. The training set was used to build an equation, which is tested by the remaining fold. In each iteration, three accuracy measures are calculated: Mean Magnitude of Relative Error (MMRE), percentages of the estimate under $25 \%$ of error Pred(25) and Mean Absolute Residual (MAR). The definition and interpretation of each measure are presented in Appendix B.

The paired T-Test was used to compare the difference between the median and predicted model, in other words, to check if there is a statistically significant difference between the mean and the predicted model. The test helped to check if the predicted model could be used [60].

The T-Test's null hypothesis is that the mean difference is zero [61]. In other words, the rejection of the null hypothesis implies a similarity of the two variables. Therefore, $p>0.05$ means that the median and predicted models are similar. 
Table 4

Alternatives and their scores added in the final DMS score [57].

\begin{tabular}{|c|c|c|}
\hline ID & Description & Added Score \\
\hline $\mathrm{AI}$ & $\begin{array}{l}\text { You solve the problem or make the decision yourself using the information available to you at the } \\
\text { present time. }\end{array}$ & 0 \\
\hline CII & $\begin{array}{l}\text { You share the problem with your subordinates in a group meeting. In this meeting, you obtain their } \\
\text { ideas and suggestions. Then you make the decision that may or may not reflect your subordinates' } \\
\text { influence. }\end{array}$ & 8 \\
\hline
\end{tabular}

Finally, the third research question aimed at checking whether demographic variables (i.e., age, role, educational level, and experience) moderate the relationship between DMS and personality factors. In this case, we employed a hierarchical linear regression approach. It is important to highlight that when using hierarchical linear regression to inspect the moderation effect of a variable $\mathrm{M}$, the moderator is included in the predictor terms (IV) and then, in the second step, the interaction terms (IV $\times$ M). The decision about the moderation effect is made by verifying the model significance $(p<0.05)$ and the change in the $R^{2}$.

\section{Results}

The research reported herein has three research questions, as detailed on Section 3. This section presents the results of the analysis related to each one. A deeper meaning of the results is discussed on Section 5 .

\subsection{RQ 01 - the existence of a relationship between decision-making style and personality factors and facets}

The existence of a potential relationship between DMS and personality variables (the personality factors and personality facets - RQ 01) was inspected using Spearman's correlation. Table 5 shows the correlation coefficients (r), and the level of significance $(p<0.05)$ for the correlation analysis between DMS and personality variables. The number of data points used to execute the analysis is 63 .

The statistically significant correlations are those with $p<0.05$. Results showed that Agreeableness was the only personality factor significantly correlated with DMS $(\mathrm{r}(63)=0.224, \mathrm{p}=0.039)$; and that six personality facets were also statistically significantly correlated with DMS, as follows:

1. Anger (N2) $(\mathrm{r}(63)=-0.240, p=0.029)$. This personality facet was the only one with a negative correlation coefficient, which means that the higher the DMS, the lower the N2, and vice-versa.

2. Three agreeableness facets are significantly correlated with DMS: Trust (A1) $(\mathrm{r}(63)=0.231, p=0.034)$, Altruism (A3) $(\mathrm{r}(63)=$ 0.307, $p=0.007)$, and Cooperation (A4) $(\mathrm{r}(63)=0.250, p=$ 0.024).

3. Two openness facets are also statistically significantly correlated with DMS: Emotionality $(\mathrm{O} 3)(\mathrm{r}(63)=0.230, p=0.035)$ and Liberalism $(\mathrm{O}) \mathrm{r}(\mathrm{r}(63)=0.332, p=0.004)$.
Table 5

Spearman correlation results between personality variables and decision-making style (DMS).

\begin{tabular}{|c|c|c|c|c|}
\hline \multicolumn{3}{|c|}{ Personality variables } & \multicolumn{2}{|c|}{ DMS } \\
\hline & & & $\mathbf{r}$ & $p$ \\
\hline Personality & Agreeableness & A & 0.224 & $0.039 *$ \\
\hline \multirow{4}{*}{ Factors } & Conscientiousness & $\mathrm{C}$ & -0.084 & 0.258 \\
\hline & Extraversion & $\mathrm{E}$ & 0.100 & 0.219 \\
\hline & Neuroticism & $\mathrm{N}$ & -0.049 & 0.352 \\
\hline & Openness & $\mathrm{O}$ & 0.191 & 0.067 \\
\hline Agreeableness & Trust & $\mathrm{A} 1$ & 0.231 & 0.034 * \\
\hline \multirow[t]{5}{*}{ Facets } & Morality & A2 & 0.051 & 0.345 \\
\hline & Altruism & A3 & 0.307 & $0.007^{*}$ \\
\hline & Cooperation & A4 & 0.250 & 0.024 * \\
\hline & Modesty & A5 & 0.077 & 0.275 \\
\hline & Sympathy & A6 & 0.078 & 0.272 \\
\hline \multirow{6}{*}{$\begin{array}{l}\text { Conscientious- } \\
\text { ness Facets }\end{array}$} & Self-Efficacy & $\mathrm{C} 1$ & -0.209 & 0.050 \\
\hline & Orderliness & $\mathrm{C} 2$ & -0.031 & 0.403 \\
\hline & Dutifulness & $\mathrm{C} 3$ & 0.061 & 0.316 \\
\hline & $\begin{array}{l}\text { Achievement- } \\
\text { Striving }\end{array}$ & $\mathrm{C} 4$ & -0.009 & 0.473 \\
\hline & Self-Discipline & $\mathrm{C} 5$ & -0.189 & 0.069 \\
\hline & Cautiousness & $\mathrm{C} 6$ & -0.068 & 0.299 \\
\hline Extraversion & Friendliness & E1 & 0.081 & 0.263 \\
\hline \multirow[t]{6}{*}{ Facets } & Gregariousness & $\mathrm{E} 2$ & 0.108 & 0.200 \\
\hline & Assertiveness & E3 & -0.016 & 0.452 \\
\hline & Activity Level & $\mathrm{E} 4$ & 0.007 & 0.479 \\
\hline & Excitement & E5 & 0.143 & 0.132 \\
\hline & Seeking & & & \\
\hline & Cheerfulness & E6 & 0.182 & 0.077 \\
\hline Neuroticism & Anxiety & N1 & -0.110 & 0.196 \\
\hline \multirow[t]{6}{*}{ Facets } & Anger & N2 & -0.240 & $0.029 *$ \\
\hline & Depression & N3 & 0.055 & 0.335 \\
\hline & Self- & N4 & 0.208 & 0.051 \\
\hline & Consciousness & & & \\
\hline & Immoderation & N5 & -0.050 & 0.348 \\
\hline & Vulnerability & N6 & 0.108 & 0.199 \\
\hline Openness & Imagination & $\mathrm{O} 1$ & 0.141 & 0.136 \\
\hline \multirow[t]{5}{*}{ Facets } & Artistic Interests & $\mathrm{O} 2$ & 0.020 & 0.437 \\
\hline & Emotionality & $\mathrm{O} 3$ & 0.230 & $0.035 *$ \\
\hline & Adventurousness & O4 & 0.085 & 0.255 \\
\hline & Intellect & O5 & -0.016 & 0.452 \\
\hline & Liberalism & O6 & 0.332 & $0.004 *$ \\
\hline
\end{tabular}

Observations: $\mathrm{n}$ (sample size) $=63 ; \mathrm{r}-$ correlation coefficient; $p-$ Sig. (1-tailed): *Correlation is significant at the 0.05 level (1-tailed). 
Table 6

Regression results for DMS predicted by personality factors.

\begin{tabular}{|c|c|c|c|c|c|c|c|c|c|c|c|c|}
\hline & \multicolumn{3}{|c|}{ Iteration 1} & \multicolumn{3}{|c|}{ Iteration 2} & \multicolumn{3}{|c|}{ Iteration 3} & \multicolumn{3}{|c|}{ Iteration 4} \\
\hline & B & SE & $p$ & B & SE & $p$ & B & SE & $p$ & B & SE & $p$ \\
\hline Const & 93.76 & 65.59 & 0.27 & 87.76 & 63.52 & 0.30 & 58.54 & 49.86 & 0.45 & 92.32 & 42.29 & 0.08 \\
\hline A & 0.78 & 0.53 & 0.13 & 0.73 & 0.52 & 0.15 & 0.66 & 0.51 & 0.18 & 0.91 & 0.47 & 0.08 \\
\hline C & -0.35 & 0.46 & 0.44 & -0.34 & 0.46 & 0.45 & - & - & - & - & - & - \\
\hline $\mathrm{E}$ & -0.24 & 0.58 & 0.63 & - & - & - & - & - & - & - & - & - \\
\hline $\mathrm{O}$ & 0.75 & 0.61 & 0.19 & 0.75 & 0.61 & 0.22 & 0.69 & 0.54 & 0.19 & - & - & - \\
\hline$R^{2}$ & & .09 & & & .09 & & & .08 & & & .06 & \\
\hline Adj $R^{2}$ & .03 & & & & .05 & & & .05 & & & .04 & \\
\hline $\mathrm{F}$ & & 1.5 & & & 1.97 & & & 2.69 & & & 3.75 & \\
\hline$p$ & & .22 & & & .13 & & & .08 & & & .06 & \\
\hline
\end{tabular}

Observation: $\mathrm{n}=62$.

Table 7

Accuracy of the DMS predicted model.

\begin{tabular}{cccccccc}
\hline \multirow{2}{*}{ Model } & Fold & \multicolumn{2}{c}{ Equation } & & \multicolumn{3}{c}{ Accuracy Measures } \\
& & A $^{*}$ & Const & & MMRE & MAR** & Pred(25) \\
\hline Predicted & 1 & 0.8 & 101.9 & & $19.91 \%$ & 36.28 & $76.92 \%$ \\
Model & 2 & 1.1 & 77.43 & & $11.71 \%$ & 20.65 & $100 \%$ \\
& 3 & 1.1 & 81.31 & & $30.44 \%$ & 34.00 & $63.64 \%$ \\
& 4 & 0.8 & 105.5 & & $18.36 \%$ & 28.60 & $78.57 \%$ \\
& 5 & 0.9 & 88.56 & & $24.22 \%$ & 37.87 & $66.67 \%$ \\
\hline Median & 1 & - & - & & $19.15 \%$ & 37.08 & $69.23 \%$ \\
Model & 2 & - & - & & $9.89 \%$ & 16.40 & $80.00 \%$ \\
& 3 & - & - & & $27.67 \%$ & 31.18 & $63.64 \%$ \\
& 4 & - & - & & $19.15 \%$ & 30.07 & $85.71 \%$ \\
& 5 & - & - & $27.73 \%$ & 42.47 & $60.00 \%$ \\
\hline
\end{tabular}

*A = Agreeableness. ${ }^{*}$ DMS scores vary from 30 to 300 .

Section 5 will discuss these results. The following section presents the regression analysis, considering the DMS as the response variable and the personality factors as predictor variables.

\subsection{RQ 02 - use of personality factors to explain the variation in decision- making style values}

In order to investigate whether personality factors could predict DMS (RQ 02), we carried out a multiple linear regression (MLR) analysis with backward elimination of variables. In this analysis, DMS was the response variable, and four personality factors were used as independent variables (agreeableness, conscientiousness, extraversion, and openness). Neuroticism (N) was not included in the analysis because it does not have a linear relationship with DMS. We checked different combinations of transformations on DMS and personality factors. Only the transformation $1 / x^{4}$ on DMS and $\mathrm{N}$ solves the linearity problem. However, with this transformation, none of the factors are selected in the backward regression. Therefore, we decided to exclude Neuroticism from the analysis.

No multicollinearity was observed (Variance Inflation Factor VIF $<1.5$ in all iterations and for all variables). The data met the assumption of errors' independence (Durbin-Watson value $=1.772$ ); furthermore, errors do not show a significant deviation from a normal distribution $(\mathrm{W}(62)=0.987, p=0.760)$, and they are homogeneously distributed (Breusch-Pagan test, $\mathrm{F}(1,61)=.335 ; p=0.565){ }^{4}$ Table 6 presents the results of the MLR with backward elimination of variables.

Table 6 shows that the backward elimination procedure removed one variable per iteration resulting in an MLR with four iterations. Only agreeableness was selected to explain the variation in DMS $\left(\operatorname{Adj} . R^{2}=\right.$ $0.04, p=0.05$ ). We employed 5-fold cross-validation to assess model accuracy. The results are shown in Table 7.

4 One datapoint was removed to keep the homoscedasticity of the error distribution. One datapoint was removed to keep the homoscedasticity of the error distribution.
Table 7 shows a predicted model with overall good accuracy. The MMRE values range from $11.71 \%$ to $30.44 \%$, and the MAR shows the errors in absolute numbers, and it ranges from 20.655 to 37.869 . The Pred(25) values show that at least $63.64 \%$ of the prediction error is lower than $25 \%$.

However, these values do not differ widely from the median model accuracy values. Therefore, we run a paired T-Test to compare the absolute residuals values from the mean model and the same values produced by the predicted models. We did not find a significant difference in the values predicted model $(\mathrm{M}=32.07, \mathrm{SD}=25.14)$ and the mean model $(\mathrm{M}=32.49, \mathrm{SD}=26.09) ; \mathrm{t}(62)=0.309, \mathrm{p}=0.759$.

4.3. RQ 03 - the moderation effect of demographic variables in the decision-making style and personality relationship

We also run a hierarchical linear regression to inspect the moderation effect of demographic variables (i.e., age, educational level, experience, and role) in the relationship between agreeableness (A) and DMS (RQ 03). An illustration of the model and equation explored in our analysis is presented in Fig. 4.

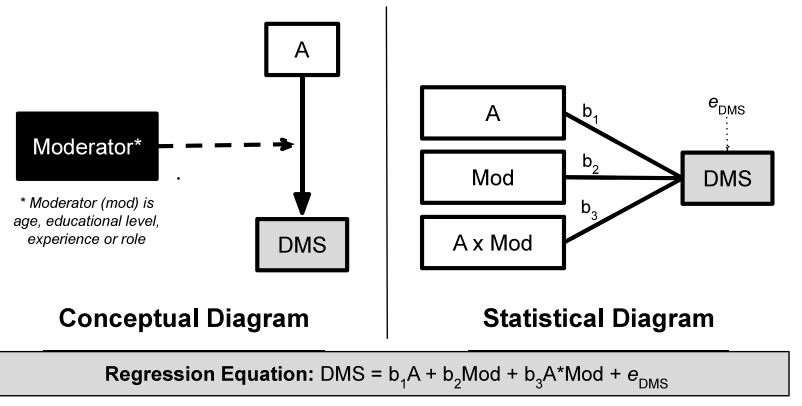

Fig. 4. Conceptual diagram, statistical diagram, and regression equation of the moderation analysis.

We ran four hierarchical linear regressions, one for each moderator (i.e., age, educational level, experience, and role). Due to the nature of the moderators' data (ordinal or nominal scale), we created dummy variables to represent them.

The data met all the regression assumptions (normality, linearity, independence error, and homoscedasticity) for all four hierarchical regressions. The results related to the moderation effect of age and experience in DMS are presented in Table 8, and the results associated with the effect of educational level and role in DMS are showed in Table 9.

The hierarchical model we ran using age, experience, and educational level as moderators (Tables 8 and 9, left side) resulted in a non-significant model $(p>0.05)$. This means that those variables (i.e., age, experience, and educational level) do not have a significant effect on moderating the relationship between DMS and Agreeableness. However, the hierarchical model we run for the variable "role" provided different results.

Table 9 (right side) shows the hierarchical regression to inspect the moderation effect of the variable "role". Observe that both steps resulted in models statistically significant $(p<0.05)$. The coefficient of interaction term int1 has significance slightly superior to 0.05 (B = $2.16, p=0.065)$ and the change in the $R^{2}$ is near to $5 \%\left(R^{2}\right.$ change $=0.049$ ). Therefore, we decided to visualize the effect of role in the relationship DMS-A.

The variable "role" is nominal and can assume four different values: business, management, technical, and mixed. As mentioned in the notes of Table 9 (right side), we did not consider the value "business" in the analysis because it has only one data point, which makes the prediction impossible.

In order to illustrate the moderation effect of role, we took the equation predicted by the second step of the hierarchical regression and created a graphic for that equation. The result is shown in Fig. 5. 


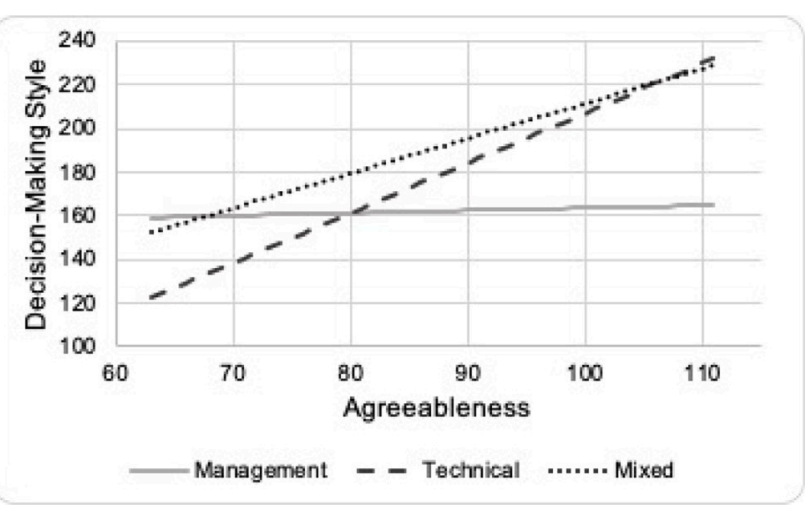

Fig. 5. Moderation effect of role in the relationship between DMS and Agreeableness.

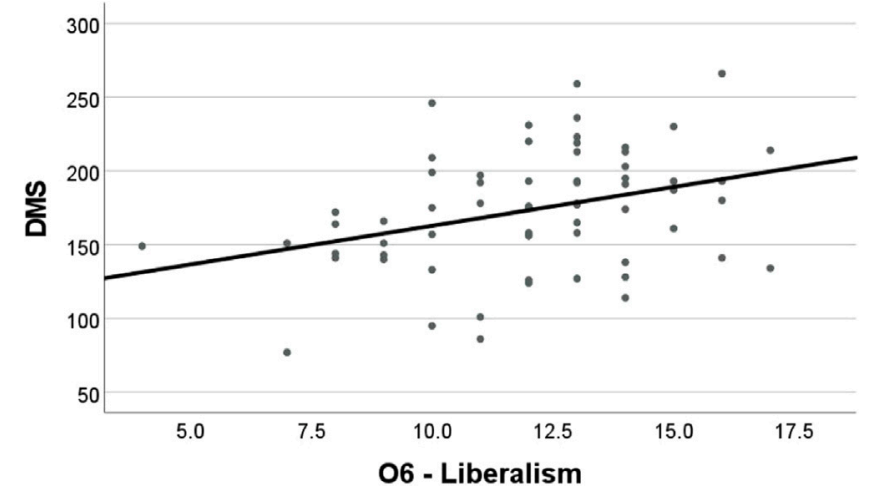

Fig. 6. The scatterplot of the relationship between DMS and O6 (liberalism, r(63) = $0.332, p=0.004)$.

Table 10

Individual characteristics that vary similarly to DMS score.

\begin{tabular}{|c|c|c|c|}
\hline \multicolumn{2}{|c|}{ Positive correlation coefficient } & \multicolumn{2}{|c|}{ Negative correlation coefficient } \\
\hline Facet & Characteristics & Facet & Characteristics \\
\hline A1 & $\begin{array}{l}\text { Fair, honest, and have good } \\
\text { intentions }\end{array}$ & N2 & $\begin{array}{l}\text { Feel enraged when things do } \\
\text { not go in their way }\end{array}$ \\
\hline A3 & Like to assist other & & \\
\hline A4 & $\begin{array}{l}\text { Dislike confrontation; they } \\
\text { can easily compromise their } \\
\text { own needs to get along with } \\
\text { others }\end{array}$ & & \\
\hline $\mathrm{O} 3$ & Aware of own feelings & & \\
\hline O6 & $\begin{array}{l}\text { Ready to challenge } \\
\text { authority, convention, and } \\
\text { traditional values }\end{array}$ & & \\
\hline \multicolumn{2}{|c|}{$\begin{array}{l}\text { People with more participative } \\
\text { decision-making style (high DMS } \\
\text { score) tends to have more of these } \\
\text { individual characteristics. }\end{array}$} & \multicolumn{2}{|c|}{$\begin{array}{l}\text { People with less participative } \\
\text { decision-making style (low DMS } \\
\text { score) tends to have more of these } \\
\text { individual characteristics }\end{array}$} \\
\hline
\end{tabular}

Table $10^{5}$ shows all the personality facets with a statistically significant correlation to DMS, along with the characteristics of people with a high score in the related personality facet.

Only one personality facet (N2, anger) has a negative correlation coefficient (Table 10), meaning that the N2 and DMS scores grow in different directions, or in other words, when N2's score is high, the DMS's score tends to be low, as shown in Fig. 7. For the same reason mentioned for the scatterplot on Fig. 6, it is not easy to see

5 The characteristics presented on Table 10 for each personality facet were adapted from [62].

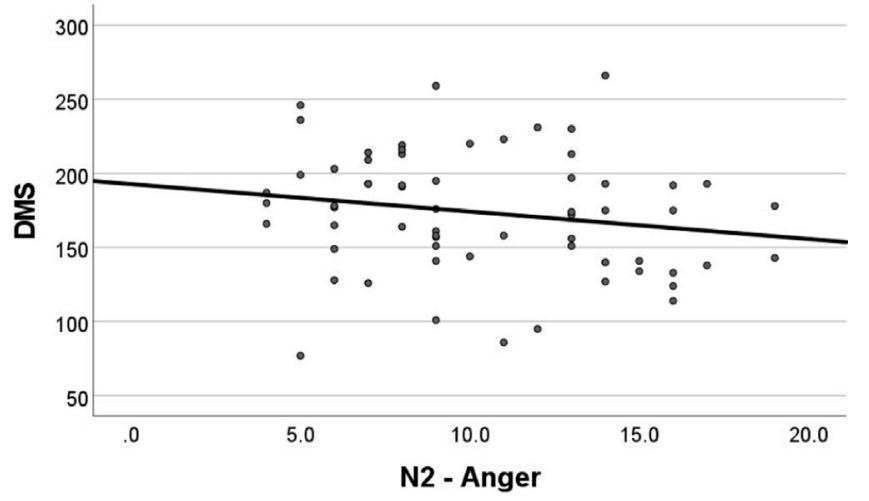

Fig. 7. The scatterplot of the relationship between DMS and N2 (anger, $r(63)=-0.240$, $p=0.029$ ).

the proportional change in DMS values with the changes on $\mathrm{N} 2$ values visually $(\mathrm{r}=-0.240)$.

It is important to highlight that a significant correlation does not mean a cause-effect relationship. The correlation shows only a tendency of two variables to grow in a similar pattern, in the same or opposite direction. Our analysis showed that the similarity between personality facets and DMS is low because the correlation coefficient is lower than 0.7 in all cases.

In relation to the personality factors, only agreeableness is statistically significantly correlated with DMS (Table 5). It has a positive coefficient and a not strong correlation $(\mathrm{r}(63)=0.224<0.7, p=0.039$ ).

Agreeableness was also selected in the regression analysis to explain $4.2 \%$ of variation in DMS $\left(\mathrm{F}(1,61)=3.745\right.$, Adj. $R^{2}=0.042, p=$ 0.058 ), as shown in Table 6 . The coefficient of agreeableness in the regression model is positive ( $\mathrm{B}=0.908, p=0.081$ ), which means that an increment in the agreeableness level impacts on an increment of DMS score (more participative decision-making style).

The decision-making style (DMS) is about how much the stakeholders participate in the decision-making process. A high level of agreeableness describes people who always assume the best of others [63]. Thus, it is easier for people with high agreeableness level to believe that others' participation in the decision-making process will contribute positively to the decision.

Observe that the significance of the model selected by the regression procedure (Table 65 ) is slightly superior to the threshold $(0.05)$ as well as the coefficient significance of agreeableness. Furthermore, the percentage of explanation is low at only $4.2 \%$. However, the cross-validation procedure (Table 7) shows a satisfactory prediction accuracy, with absolute error numbers (MAR) ranging from 20.65 to 37.869. Considering that the DMS score ranges from 30 to 300 , an error between 20 and 40 units is small.

We also compared the median and predicted models using paired T-Test, which showed no statistically significant difference between them. Therefore, our tests showed using the mean model has the same prediction accuracy as the model herein predicted. Therefore, further investigation is needed, using a larger dataset, and also perhaps by gathering data from a more diverse population within Brazil, and worldwide.

Regarding the moderation effect of demographic variables in the relationship between DMS and A, our analysis showed that age, educational level, and experience do not modify the abovementioned relationship.

However, the variable "role" moderates the relationship between DMS and A. The results showed that when the value of "role" is management, no effect in the relationship DMS-A is observed. However, when "role" assumes the value technical or mixed, the relationship DMS-A becomes stronger, as illustrated in Fig. 8. 


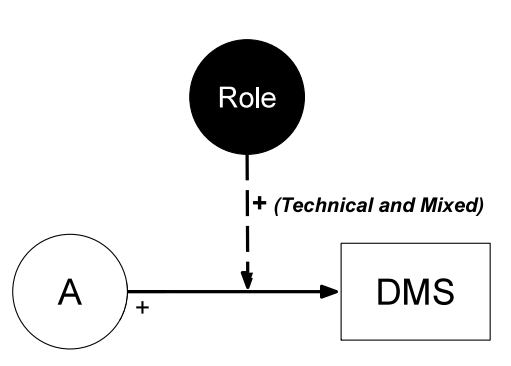

Fig. 8. The moderation effect of role on the relationship between DMS and Agreeableness.

This result makes sense because people who perform technical or mixed roles do not necessarily have been trained in management skills (including those related to decision-making). Therefore, the lack of training might impact the preference for a more participative decisionmaking process (high DMS scores) because, in this way, the decisionmaker leaders can get some help from others in the team.

\section{Threats to the validity}

The research validity is an important discussion because it assesses how close to the real world are the conclusions we made [64]. The construct validity refers to the measurements and, applying to the survey study presented herein, if the instrument employed actually measures what it is intended to measure [65]. On this context, the personality and decision-making style questionnaire has been used and tested before, however they were written originally in English. Because of our survey population is composed by Brazilians, we translated the questionnaires to Brazilian Portuguese. These translations were reviewed twice, first during the survey pilot and then by a third-party person. However, maybe we introduced some errors during the translation process and this might have some impact in the measurement.

External validity is another important aspect of validity; which relates to the generalizability of the findings [50]. The main problem here is related to the survey population. The first problem is the small sample size (only 63 data-points) due to the long DMS questionnaire, which takes from 1.5 to $3 \mathrm{~h}$ to be filled. A small sample size can result in a low statistical power, in other words, it affects the probability of a statistically significant finding actually means a true effect $[66,67]$.

Another problem related to the survey population is its geographic distribution. Although the survey participants work in either Brazil or abroad, they are all Brazilians, and have mostly technical roles. These characteristics can impact the generalization power of the survey results; therefore, one of the future work avenues is to replicate this survey with participants who have other nationalities and work outside Brazil, with a mix of different roles.

Finally, among the threats to the internal validity of a survey research mentioned by Fink [68], the only threat we found is related to the selection of participants. All the participants were the first author's acquaintances, in other word, we used a non-probabilistic convenience sample. The sampling method implies that not all members of the aimed population had the equal chance to participate in this study and it can have impact in the randomization. We applied snowballing to expand the survey population and, therefore, to deal with this potential threat. However, this might impact in the internal validity of the research results.

\section{Conclusions}

This investigation contributes to an understanding of the relationship between decision-making and personality. The research results show that despite the relationship between decision-making style and
Table 11

Frequency of responses for the demographic variables gender, age, educational level, experience and role.

\begin{tabular}{|c|c|c|c|c|c|}
\hline Gender & $\#$ & $\%$ & Experience & $\#$ & $\%$ \\
\hline Male & 43 & $68.3 \%$ & Internship & 2 & $3.2 \%$ \\
\hline \multirow[t]{2}{*}{ Female } & 20 & $31.7 \%$ & $<2$ years & 3 & $4.8 \%$ \\
\hline & & & $2-5$ years & 20 & $31.7 \%$ \\
\hline Age & $\#$ & $\%$ & $6-10$ years & 10 & $15.9 \%$ \\
\hline$<=25$ & 5 & $7.9 \%$ & $11-15$ years & 16 & $25.4 \%$ \\
\hline $26-35$ & 36 & $57.1 \%$ & $>16$ years & 12 & $19 \%$ \\
\hline $36-45$ & 11 & $17.5 \%$ & & & \\
\hline $46-55$ & 7 & $11.1 \%$ & Role & $\#$ & $\%$ \\
\hline \multirow[t]{2}{*}{$>55$} & 4 & $6.3 \%$ & Business & 1 & $1.6 \%$ \\
\hline & & & Technical & 30 & $47.6 \%$ \\
\hline Education & $\#$ & $\%$ & Mixed & 19 & $30.2 \%$ \\
\hline High School & 2 & $3.2 \%$ & & & \\
\hline Bachelor & 37 & $58.7 \%$ & & & \\
\hline Master & 16 & $25.4 \%$ & & & \\
\hline $\mathrm{PhD}$ & 8 & $12.7 \%$ & & & \\
\hline
\end{tabular}

Notes: - for all variables the total number of data-points is 63 ; $=$ number of responses; $\%=$ percentage of responses.

personality has not been discussed in the Software Engineering context, this relationship exists, and one's personality characteristics influence the decision-making style.

We found out that the personality factor agreeableness is statistically significantly correlated to DMS and also six personality facets. However, the highest correlation coefficient is 0.332 , which shows these relationships are not strong because the highest correlation coefficient is lower than 0.7 .

Our regression model explains $4.2 \%$ of DMS variation, which indicates an effect of personality characteristics, in special agreeableness, on the decision-making style. The model accuracy is good; however a TTest showed no advantage to use the predicted model instead of median model (Section 5).

Finally, we found out that the variable "role" moderates the relationship between DMS and Agreeableness. The results pointed out that, when the role is technical or mixed, the effect for agreeableness in DMS is increased.

As future work, the three categories of roles (check 3.1) could be expanded upon, for example, focusing on the different technical roles necessary for software development. This change leads to a more detailed analysis of the moderation effect of "role" on the abovementioned relationship.

The decision-making style questionnaire designed by Vroom and Yetton [16] and employed in this research is composed of 30 decisionmaking problems collected on companies from different segments (such as the chemical industry, energy industry, etc.) Therefore, an important future work is to update the set of problems with situations that software engineers may actually face during their tasks.

Furthermore, the decision-making style questionnaire can take between $1.5 \mathrm{~h}$ to $3 \mathrm{~h}$ to answer (Section 3.4. Therefore, another important future work is to investigate how to decrease the time required to answer it.

The abovementioned improvement could also help other important future work: collect more data, especially from respondents representing different countries. A more diversified sample might impact the survey results. Furthermore, with more data, it may be possible to identify more statistically significant correlations and predictors.

With more data points, it would also be possible to investigate the prediction of decision-making style using both personality facets and personality factors. This type of analysis would provide a more detailed snapshot of the relationship between decision-making and personality.

It is also important to highlight that our regression model's explanatory power is not high (only $4.2 \%$ ), which suggests that there may be 
other additional factors that can jointly predict decision-making style. Therefore, a great opportunity for future works is to also explore other factors.

The cause-effect relationship related to the regression model herein presented could also be further investigated considering other research designs (experiments, for example) and data analysis approaches (interviews, for example).

Finally, and maybe the most important future work related to this research is developing techniques to help managers who should lead a specific decision-making, considering the candidates' personality profile.

\section{CRediT authorship contribution statement}

Fabiana Mendes: Writing - original draft, Visualization, Investigation, Formal analysis, Methodology, Conceptualization. Emília Mendes: Supervision, Validation, Writing - review \& editing. Norsaremah Salleh: Supervision, Validation, Writing - review \& editing. Markku Oivo: Supervision, Project administration.

\section{Declaration of competing interest}

The authors declare that they have no known competing financial interests or personal relationships that could have appeared to influence the work reported in this paper.

Appendix A. Descriptive statistics of survey variables

Table 11 shows the frequency for the demographic variables. These variables are important to understand the survey population and, except for gender, they are also used to verify the moderation effect on the relationship between decision-making style and personality variables.

The distribution of DMS and personality variables are presented in Table 12. The theoretical score range of DMS is from 0 to 300 , as explained in Section 3.4. For the personality factors, the theoretical score range is between 24 to 120 , and for personality facets between 4 to 20 (more details in Section 3.4).

\section{Appendix B. Definitions and interpretations of accuracy measures}

The accuracy of the model presented in this paper was calculated considering three different measures: the mean magnitude of relative error (MMRE), percentages of the estimate under $25 \%$ error or Pred(25), and mean absolute residual (MAR). The definition and interpretation of each one are presented following [69,70]. On the MMRE and MAR formula, $x_{i}$ is the actual value; $x$ is the estimated value; and $n$ the dataset size.

- MMRE $=\frac{1}{n}\left(\sum_{i=1}^{n}\left(\frac{\left|x_{i}-x\right|}{x_{i}}\right)\right)$. The closer MMRE is to zero, the greater the accuracy.

- $\operatorname{Pred}(25)=$ Percentage of estimates whose error is less than or equal to $25 \%$. The closer this value is to $100 \%$, the greater the accuracy.

- MAR $=\frac{1}{n}\left(\sum_{i=1}^{n}\left(\left|x_{i}-x\right|\right)\right)$. Smaller values indicate higher accuracy. To interpret this measure, the reader needs to know the DV range.

Although Shepperd and MacDonnell [70] advocate that the MMRE can lead to bias toward an under-estimated model prediction, we decided to include this measure, as it has a more straightforward interpretation than MAR. With all three measures - MMRE, Pred(25), and MAR - we can compare their accuracy estimates and decide our regression equations' overall accuracy. In this way, we eliminate any possible bias when it comes to accuracy.

In order to help interpret the results, we employed the following levels of accuracy on the MMRE measures:

- MMRE $\geq 25 \%$ : good accuracy

- 25\% < MMRE $\leq 40 \%$ : moderate accuracy

- MMRE > 40\%: poor accuracy
Table 12

Descriptive statistics of DMS and personality variables.

\begin{tabular}{|c|c|c|c|c|c|}
\hline Variable & Min & Max & Mean & Median & Std. Dev. \\
\hline DMS & 77.00 & 266.00 & 173.59 & 175.00 & 41.11 \\
\hline A & 48.00 & 111.00 & 89.51 & 92.00 & 10.89 \\
\hline $\mathrm{A} 1$ & 5.00 & 20.00 & 13.10 & 14.00 & 3.39 \\
\hline $\mathrm{A} 2$ & 10.00 & 20.00 & 18.30 & 19.00 & 1.82 \\
\hline A3 & 7.00 & 20.00 & 15.52 & 16.00 & 2.72 \\
\hline A4 & 7.00 & 20.00 & 16.71 & 17.00 & 3.02 \\
\hline A5 & 4.00 & 19.00 & 11.30 & 11.00 & 3.13 \\
\hline A6 & 4.00 & 20.00 & 14.57 & 15.00 & 3.03 \\
\hline $\mathrm{C}$ & 59.00 & 112.00 & 92.92 & 93.00 & 11.28 \\
\hline $\mathrm{C} 1$ & 8.00 & 20.00 & 15.44 & 16.00 & 2.27 \\
\hline $\mathrm{C} 2$ & 5.00 & 20.00 & 15.43 & 16.00 & 4.02 \\
\hline $\mathrm{C} 3$ & 10.00 & 20.00 & 16.79 & 17.00 & 2.22 \\
\hline $\mathrm{C} 4$ & 11.00 & 20.00 & 16.35 & 16.00 & 2.28 \\
\hline C5 & 4.00 & 20.00 & 14.17 & 15.00 & 2.95 \\
\hline C6 & 4.00 & 20.00 & 14.73 & 15.00 & 3.66 \\
\hline $\mathrm{E}$ & 46.00 & 96.00 & 76.11 & 78.00 & 10.64 \\
\hline E1 & 6.00 & 20.00 & 14.10 & 14.00 & 3.17 \\
\hline E2 & 4.00 & 17.00 & 10.70 & 11.00 & 3.36 \\
\hline E3 & 7.00 & 20.00 & 14.67 & 15.00 & 3.10 \\
\hline E4 & 7.00 & 19.00 & 12.94 & 13.00 & 2.59 \\
\hline E5 & 4.00 & 17.00 & 8.71 & 8.00 & 2.88 \\
\hline E6 & 9.00 & 20.00 & 15.00 & 15.00 & 2.33 \\
\hline $\mathrm{N}$ & 36.00 & 93.00 & 65.90 & 67.00 & 13.28 \\
\hline $\mathrm{N} 1$ & 6.00 & 19.00 & 12.60 & 13.00 & 3.48 \\
\hline N2 & 4.00 & 19.00 & 10.35 & 9.00 & 4.05 \\
\hline N3 & 4.00 & 17.00 & 8.17 & 8.00 & 2.92 \\
\hline N4 & 7.00 & 20.00 & 13.08 & 13.00 & 2.80 \\
\hline N5 & 6.00 & 18.00 & 10.51 & 10.00 & 2.53 \\
\hline N6 & 5.00 & 17.00 & 11.19 & 11.00 & 2.77 \\
\hline $\mathrm{O}$ & 54.00 & 104.00 & 81.00 & 81.00 & 10.12 \\
\hline $\mathrm{O} 1$ & 8.00 & 20.00 & 14.49 & 14.00 & 3.03 \\
\hline $\mathrm{O} 2$ & 4.00 & 20.00 & 13.65 & 14.00 & 3.57 \\
\hline $\mathrm{O} 3$ & 6.00 & 20.00 & 14.43 & 15.00 & 2.96 \\
\hline O4 & 5.00 & 19.00 & 12.22 & 12.00 & 3.10 \\
\hline O5 & 9.00 & 20.00 & 14.16 & 14.00 & 2.77 \\
\hline O6 & 4.00 & 17.00 & 12.05 & 12.00 & 2.68 \\
\hline
\end{tabular}

Observations: for all variables the total number of data-points is 63 . The meaning of each variable's acronym presented here can be found in Fig. 2.

Appendix C. Scatterplot of relationships with significant correlation

Figures Figs. 9-15 show the scatterplots of decision-making style and personality, but only those with a statistically significant correlation (check Table 5).

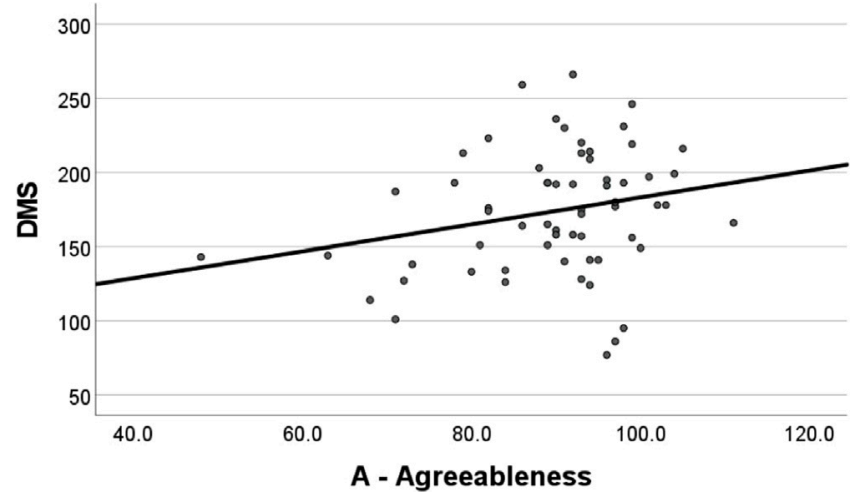

Fig. 9. The scatterplot of the relationship between DMS and Agreeableness $(r(63)=$ $0.224, p=0.039$ ). 


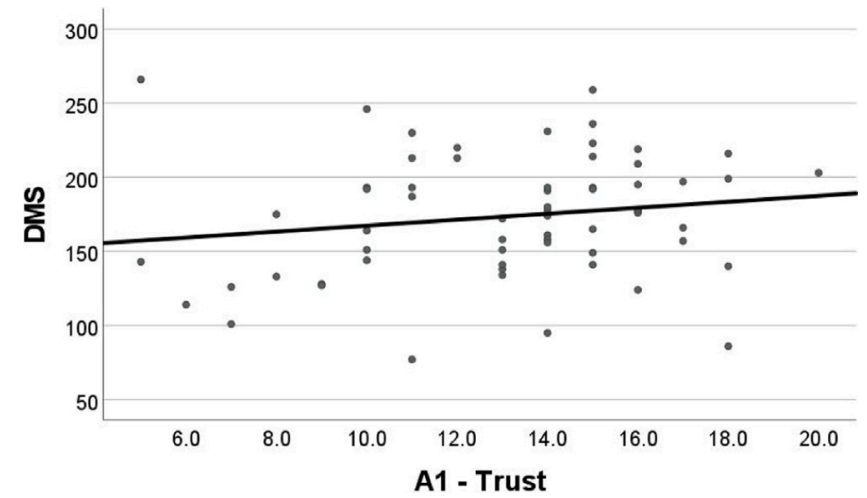

Fig. 10. The scatterplot of the relationship between DMS and $\mathrm{A} 1(\mathrm{r}(63)=0.231, p=$ $0.034)$.

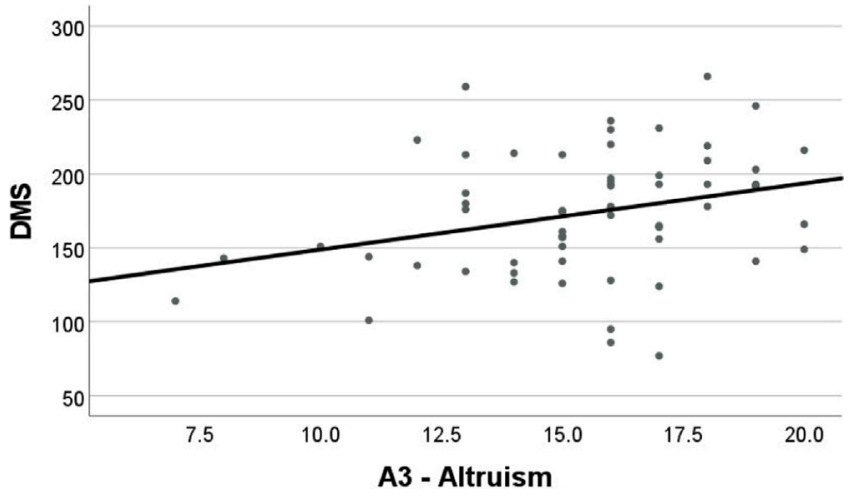

Fig. 11. The scatterplot of the relationship between DMS and A3 $(r(63)=0.307, p=$ 0.007).

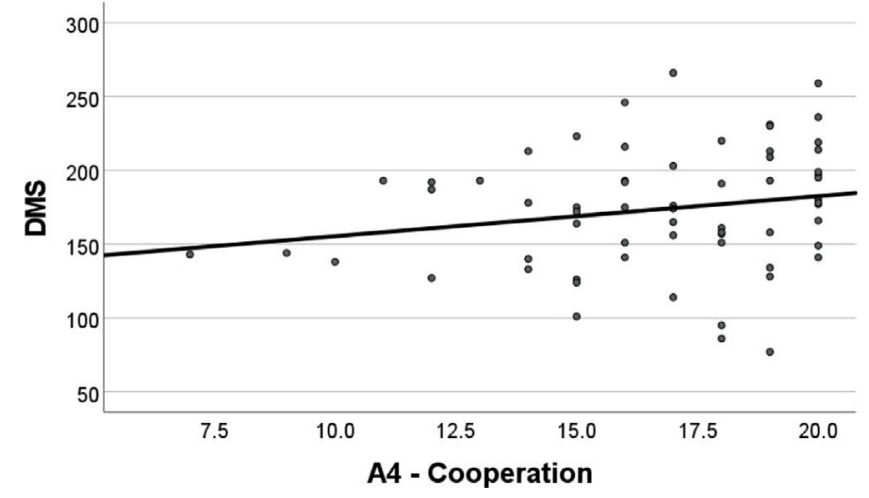

Fig. 12. The scatterplot of the relationship between DMS and A4 $(\mathrm{r}(63)=0.250, p=$ 0.024).

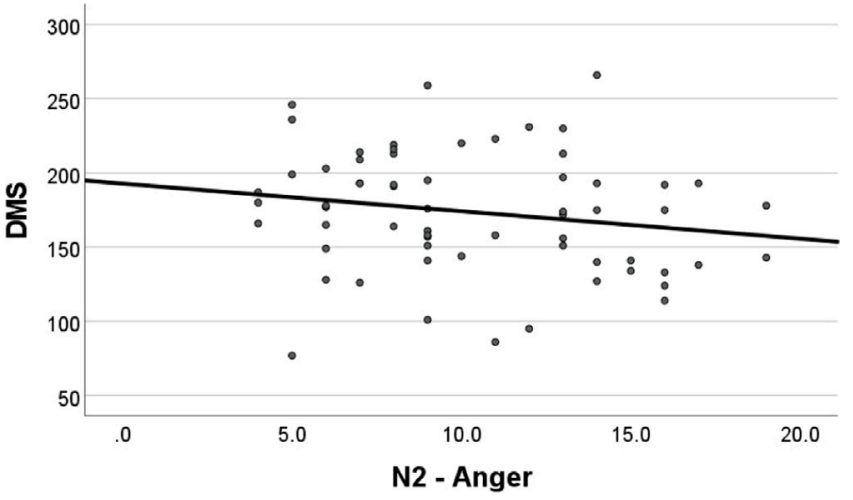

Fig. 13. The scatterplot of the relationship between DMS and $\mathrm{N} 2(\mathrm{r}(63)=-0.240, p$ $=0.029$ ).

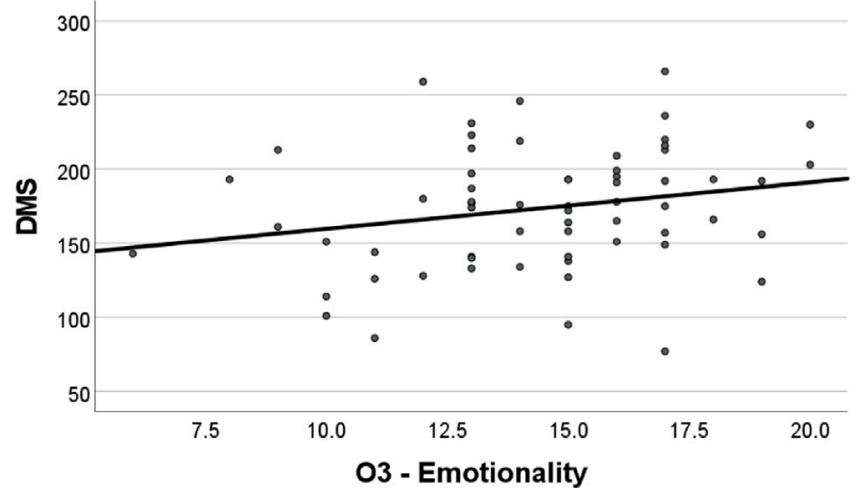

Fig. 14. The scatterplot of the relationship between DMS and $\mathrm{O} 3(\mathrm{r}(63)=0.230, p=$ 0.035).

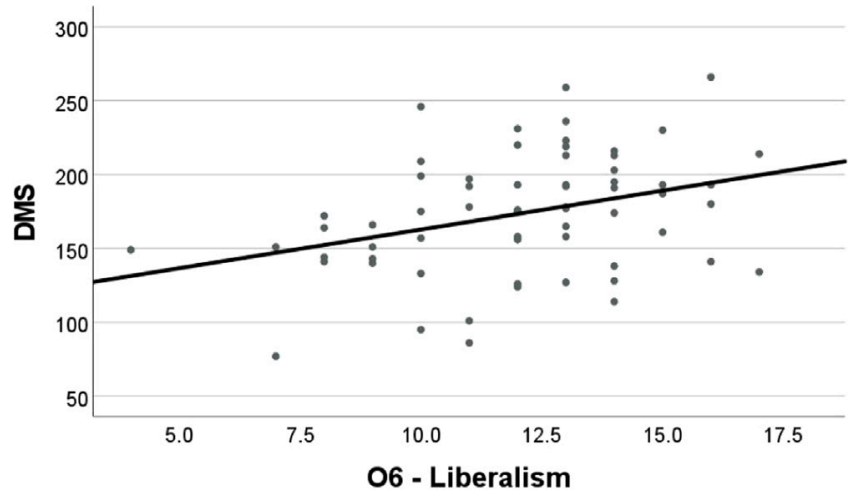

Fig. 15. The scatterplot of the relationship between DMS and O6 (liberalism, r(63) = $0.332, p=0.004)$

\section{References}

[1] D. Schön, From technical rationality to reflection-in-action, in: Supporting Lifelong Learning: Volume I: Perspectives on Learning, Routledge, 2001, p. 40.

[2] J.E. Burge, J.M. Carroll, R. McCall, I. Mistrí k, Decision-making in software engineering, in: Rationale-Based Software Engineering, Springer, Berlin, Heidelberg, 2008, pp. 67-76, http://dx.doi.org/10.1007/978-3-540-77583-6 5.

[3] R.N. Charette, Why software fails [software failure], IEEE Spectrum 42 (9) (2005) 42-49.

[4] Ö. Albayrak, H. Kurtoglu, M. Biçakçi, Incomplete software requirements and assumptions made by software engineers, in: 2009 16th Asia-Pacific Software Engineering Conference, 2009, pp. 333-339, http://dx.doi.org/10.1109/APSEC. 2009.39.

[5] K. Power, R. Wirfs-Brock, An exploratory study of naturalistic decision making in complex software architecture environments, in: European Conference on Software Architecture, 11681, Springer, Cham, 2019, pp. 55-70, http://dx.doi. org/10.1007/978-3-030-29983-5_4.

[6] J. Coelho, M.T. Valente, Why modern open source projects fail, in: Proceedings of the 2017 11th Joint Meeting on Foundations of Software Engineering, ESEC/FSE 2017, Association for Computing Machinery, New York, NY, USA, 2017, pp. 186-196, http://dx.doi.org/10.1145/3106237.3106246.

[7] S.P. Fitzgerald, Decision Making, first ed., Capstone Publ., Oxford, 2002, pp. 12-16 (Chap. 1).

[8] T. Dybå, N. Maiden, R. Glass, The reflective software engineer: Reflective practice, IEEE Softw. 31 (4) (2014) 32-36, http://dx.doi.org/10.1109/MS.2014. 97.

[9] K. Dorst, The core of 'design thinking' and its application, Des. Stud. 32 (6) (2011) 521-532, Interpreting Design Thinking.

[10] M. Razavian, A. Tang, R. Capilla, P. Lago, In two minds: how reflections influence software design thinking, J. Softw.: Evol. Process 28 (6) (2016) 394-426.

[11] I. Lytra, U. Zdun, Supporting architectural decision making for systems-of-systems design under uncertainty, in: Proceedings of the First International Workshop on Software Engineering for Systems-of-Systems, SESoS '13, Association for Computing Machinery, New York, NY, USA, 2013, pp. 43-46, http://dx.doi.org/ $10.1145 / 2489850.2489859$.

[12] V.H. Vroom, A.G. Jago, Decision making as a social process: Normative and descriptive models of leader behavior, Decis. Sci. 5 (4) (1974) 743-769. 
[13] I. Malavolta, H. Muccini, S.R. V., Enhancing architecture design decisions evolution with group decision making principles, in: I. Majzik, M. Vieira (Eds.), International Workshop on Software Engineering for Resilient Systems 2014, in: Lecture Notes in Computer Science, vol. 8785, Springer, Cham, 2014, pp. 9-23, http://dx.doi.org/10.1007/978-3-319-12241-0_2.

[14] G. Abatecola, G. Mandarelli, S. Poggesi, The personality factor: how top management teams make decisions. A literature review, J. Manag. Governance 17 (4) (2013) 1073-1100, http://dx.doi.org/10.1007/s10997-011-9189-y.

[15] F.F. Mendes, E. Mendes, N. Salleh, The relationship between personality and decision-making: A systematic literature review, Inf. Softw. Technol. 111 (2019) $50-71$.

[16] V.H. Vroom, P.W. Yetton, Leadership and Decision-Making, University of Pittsburgh Pre, 1973, Retrieved from: https://digital.library.pitt.edu/islandora/ object/pitt\%3A31735057897062/viewer. (Last access on October 2019).

[17] J. McAvoy, T. Butler, The role of project management in ineffective decision making within agile software development projects, Eur. J. Inf. Syst. 18 (4) (2009) 372-383, http://dx.doi.org/10.1057/ejis.2009.22.

[18] S. Easterbrook, J. Singer, M.-A. Storey, D. Damian, Selecting empirical methods for software engineering research, in: Guide to Advanced Empirical Software Engineering, Springer, 2008, pp. 285-311.

[19] D. Boddy, Management: An Introduction, fourth ed., Pearson Education, Harlow, UK, 2008, p. 209.

[20] C. Williams, MGMT: Principles of Management, ninth ed., Cengage Learning, Boston, MA, 2016, p. 99.

[21] J.A.O.G. da Cunha, H.P. Moura, F.J.S. Vasconcellos, Decision-making in software project management: A systematic literature review, International Conference on ENTERprise Information Systems/International Conference on Project MANagement/International Conference on Health and Social Care Information Systems and Technologies, CENTERIS/ProjMAN / HCist 2016, Procedia Comput. Sci. 100 (2016) 947-954.

[22] N.B. Moe, A. Aurum, T. Dybå, Challenges of shared decision-making: A multiple case study of agile software development, Special Issue: Voice of the Editorial Board, Inf. Softw. Technol. 54 (8) (2012) 853-865, http://dx.doi.org/10. 1016/j.infsof.2011.11.006, URL: http://www.sciencedirect.com/science/article/ pii/S0950584911002308.

[23] M.L. Drury-Grogan, O. O'dwyer, An investigation of the decision-making process in agile teams, Int. J. Inf. Technol. Decis. Mak. 12 (06) (2013) 1097-1120, http://dx.doi.org/10.1142/S0219622013400105, Publisher: World Scientific Publishing Co..

[24] S. Coyle, K. Conboy, T. Acton, Group process losses in agile software development decision making, Int. J. Intell. Inf. Technol. 9 (2013) 38-53, http: //dx.doi.org/10.4018/jiit.2013040104.

[25] R. Colomo-Palacios, C. Casado-Lumbreras, P. Soto-Acosta, A. Garcia-Crespo, Decisions in software development projects management. An exploratory study, Behav. Inf. Technol. 32 (11) (2013) 1077-1085, http://dx.doi.org/10.1080/ 0144929X.2011.630414.

[26] A. Medina, A.J. Francis, What are the characteristics that software development project team members associate with a good project manager? Project Manag. J. 46 (5) (2015) 81-93, http://dx.doi.org/10.1002/pmj.21530, Publisher: SAGE Publications Inc.

[27] J. Rose, K. Pedersen, J.H. Hosbond, P. Kræmmergaard, Management competences, not tools and techniques: A grounded examination of software project management at WM-data, Qualitative Software Engineering Research, Inf. Softw. Technol. 49 (6) (2007) 605-624, http://dx.doi.org/10.1016/j.infsof.2007.02.005.

[28] J. Jia, P. Zhang, L.F. Capretz, Environmental factors influencing individual decision-making behavior in software projects: A systematic literature review, in: Proceedings of the 9th International Workshop on Cooperative and Human Aspects of Software Engineering, CHASE '16, Association for Computing Machinery, New York, NY, USA, 2016, pp. 86-92, http://dx.doi.org/10.1145/2897586. 2897589.

[29] R. Capilla, O. Zimmermann, C. Carrillo, H. Astudillo, Teaching students software architecture decision making, in: A. Jansen, I. Malavolta, H. Muccini, I. Ozkaya, O. Zimmermann (Eds.), Software Architecture, Springer International Publishing, 2020, pp. 231-246.

[30] P. Gaubatz, I. Lytra, U. Zdun, Automatic enforcement of constraints in real-time collaborative architectural decision making, J. Syst. Softw. 103 (2015) 128-149, http://dx.doi.org/10.1016/j.jss.2015.01.056, URL: https:// www.sciencedirect.com/science/article/pii/S0164121215000345.

[31] D.P. Schultz, S.E. Schultz, Theories of Personality, tenth ed., Cengage Learning, Belmont, SA, USA, 2016, p. 7, 229.

[32] D. Cervone, L.A. Pervin, Personality: Theory and Research, twelveth ed., Wiley, 2012, pp. 7-8, 264.

[33] C.S. Carver, M.F. Scheier, Perspectives on Personality, seventh ed., Pearson, 2012, p. 2.

[34] R.M. Bergner, What is personality? Two myths and a definition, New Ideas Psychol. 57 (2020) http://dx.doi.org/10.1016/j.newideapsych.2019.100759, URL: http://www.sciencedirect.com/science/article/pii/S0732118X19300728.

[35] F. Calefato, G. Iaffaldano, F. Lanubile, B. Vasilescu, On developers' personality in large-scale distributed projects: the case of the apache ecosystem, in: 2018 IEEE/ACM 13th International Conference on Global Software Engineering, ICGSE, IEEE, 2018, pp. 87-96.

[36] J.M. Burger, Personality, eighth ed., Cengage Learning, Belmont, CA, 2010, p. 162.
[37] J.N. Butcher (Ed.), Oxford Handbook of Personality Assessment, Oxford University Press, New York, USA, 2009, p. 306.

[38] I.B. Weiner, R.L. Greene, Handbook of Personality Assessment, John Wiley \& Sons, New Jersey, 2008, pp. 315-318.

[39] J.A. Johnson, Measuring thirty facets of the five factor model with a 120-item public domain inventory: Development of the IPIP-NEO-120, J. Res. Personal. 51 (2014) 78-89.

[40] R. Hogan, J. Johnson, S. Briggs, Handbook of Personality Psychology, first ed., Elsevier, 1997, p. 5.

[41] S. Cruz, F.Q.B. da Silva, L.F. Capretz, Forty years of research on personality in software engineering: A mapping study, Comput. Hum. Behav. 46 (2015) 94-113.

[42] A. Barroso, J.S. Madureira, M.S. Soares, R.P.C. Nascimento, Influence of human personality in software engineering - A systematic literature review, in: Proceedings of the 19th International Conference on Enterprise Information Systems, Vol. 3, SciTePress, Porto, Portugal, 2017, pp. 53-62, http://dx.doi.org/10.5220/ 0006292000530062.

[43] L. Shoaib, A. Nadeem, A. Akbar, An empirical evaluation of the influence of human personality on exploratory software testing, in: 2009 IEEE 13th International Multitopic Conference, 2009, pp. 1-6, http://dx.doi.org/10.1109/ INMIC.2009.5383088.

[44] R. Feldt, R. Torkar, L. Angelis, M. Samuelsson, Towards individualized software engineering: empirical studies should collect psychometrics, in: Proceedings of the 2008 International Workshop on Cooperative and Human Aspects of Software Engineering, CHASE '08, Association for Computing Machinery, New York, NY, USA, 2008, pp. 49-52, http://dx.doi.org/10.1145/1370114.1370127.

[45] J.E. Hannay, E. Arisholm, H. Engvik, D.I.K. Sjoberg, Effects of personality on pair programming, IEEE Trans. Softw. Eng. 36 (1) (2010) 61-80, http://dx. doi.org/10.1109/TSE.2009.41, Conference Name: IEEE Transactions on Software Engineering.

[46] R. Müller, K. Spang, S. Ozcan, Cultural differences in decision making in project teams, Int. J. Manag. Projects Bus. (2009).

[47] R.G. Hunt, F.J. Krzystofiak, J.R. Meindl, A.M. Yousry, Cognitive style and decision making, Organ. Behav. Hum. Decis. Process. 44 (3) (1989) 436-453, http://dx.doi.org/10.1016/0749-5978(89)90018-6.

[48] G. Klein, Implications of the Naturalistic Decision Making Framework for Information Dominance, Technical Report AL/CF-TR-1997-0155, United States Air Force Armstrong Laboratory, Klein Associates Inc., 1997.

[49] M. Selart, Understanding the role of locus of control in consultative decision-making: a case study, Manag. Decis. 43 (3) (2005) 397-412.

[50] C. Wohlin, P. Runeson, M. Höst, M.C. Ohlsson, B. Regnell, A. Wesslén, Experimentation in Software Engineering, Springer, New York, 2012, pp. 39-40, 68.

[51] M. Kasunic, Designing an Effective Survey, Technical Report, Carnegie-Mellon Univ Pittsburgh PA Software Engineering Inst, 2005, Retrieved from https: //apps.dtic.mil/dtic/tr/fulltext/u2/a441817.pdf. (Last access in October 2019).

[52] K. Schwaber, J. Sutherland, The scrum guide. The definitive guide to scrum: The rules of the game, 2017, Retrieved from: https://www.scrumguides.org/docs/ scrumguide/v2017/2017-Scrum-Guide-US.pdf. (Last access on October 2019).

[53] Z. Halim, M. Atif, A. Rashid, C.A. Edwin, Profiling players using real-world datasets: Clustering the data and correlating the results with the big-five personality traits, IEEE Trans. Affect. Comput. (2017).

[54] T. Kanij, R. Merkel, J. Grundy, An empirical investigation of personality traits of software testers, in: Proceedings of the Eighth International Workshop on Cooperative and Human Aspects of Software Engineering, IEEE Press, 2015, pp. $1-7$.

[55] N. Salleh, E. Mendes, J. Grundy, G.S.J. Burch, An empirical study of the effects of personality in pair programming using the five-factor model, in: Proceedings of the 2009 3rd International Symposium on Empirical Software Engineering and Measurement, IEEE Computer Society, 2009, pp. 214-225.

[56] R. Glube, Leadership Decision Making: An Empirical Test of the Vroom and Yetton Model (Ph.D. thesis), Cranfield Institute of Technology. School of Management, 1978, Appendix B. Retrieved from http://dspace.lib.cranfield.ac.uk/ handle/1826/10268. (Last access in April 2021).

[57] V.H. Vroom, A.G. Jago, The New Leadership: Managing Participation in Organizations, first ed., Prentice-Hall, Inc, 1988.

[58] M.A. Babyak, What you see may not be what you get: a brief, nontechnical introduction to overfitting in regression-type models, Psychosom. Med. 66 (3) (2004) 411-421.

[59] A.P. Field, Discovering Statistics Using SPSS:(And Sex and Drugs and Rock'n'roll), third ed., Sage Publications, London, 2009, p. 222.

[60] E. Mendes, S. Di Martino, F. Ferrucci, C. Gravino, Effort estimation: How valuable is it for a web company to use a cross-company data set, compared to using its own single-company data set? in: Proceedings of the 16th International Conference on World Wide Web, WWW '07, Association for Computing Machinery, New York, NY, USA, 2007, pp. 963-972.

[61] S. Landau, B.S. Everitt, A Handbook of Statistical Analyses Using SPSS, first ed., Chapman and Hall/CRC, 2003, p. 41.

[62] J.A. Johnson, Descriptions Used in IPIP-NEO Narrative Report, 2019, Retrieved from http://www.personal.psu.edu/faculty/j/5/j5j/IPIPNEOdescriptions. html. (Last access in October 2019).

[63] P. Costa, R. McCrae, Revised NEO personality inventory interpretive report, 2000, Lutz, FL: Psychological Assessment Resources. 
[64] J.A. Maxwell, Qualitative Research Design: An Interactive Approach, third ed., in: Applied Social Research Methods, SAGE Publications, Inc, 2012 (Chap. 6).

[65] H.K. Wright, M. Kim, D.E. Perry, Validity concerns in software engineering research, in: Proceedings of the FSE/SDP Workshop on Future of Software Engineering Research, FoSER '10, Association for Computing Machinery, New York, NY, USA, 2010, pp. 411-414, http://dx.doi.org/10.1145/1882362.1882446.

[66] K.S. Button, J.P.A. Ioannidis, C. Mokrysz, B.A. Nosek, J. Flint, E.S.J. Robinson, M.R. Munafò, Power failure: why small sample size undermines the reliability of neuroscience, Nat. Rev. Neurosci. 14 (5) (2013) 365-376.

[67] B. Kitchenham, S.L. Pfleeger, Principles of survey research: Part 5: Populations and samples, SIGSOFT Softw. Eng. Notes 27 (5) (2002) 17-20.

[68] A. Fink, How to Conduct Surveys. A Step-By-Step Guide, fifth ed., Sage, London, 2013, p. 109.

[69] B.A. Kitchenham, L.M. Pickard, S.G. MacDonell, M.J. Shepperd, What accuracy statistics really measure, IEE Proc.-Softw. 148 (3) (2001) 81-85.

[70] M. Shepperd, S. MacDonell, Evaluating prediction systems in software project estimation, Inf. Softw. Technol. 54 (8) (2012) 820-827.

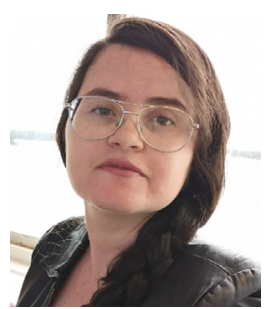

Fabiana Mendes is adjunct professor at University of Brasìlia (UnB - Brazil). She received her bachelor and master degrees both in computer science at Federal University of Goiàs. She is Ph.D. candidate at University of Oulu, Finland.

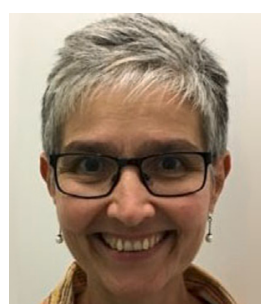

Emilia Mendes is a Full Professor at the Computer Science Department at the Blekinge Institute of Technology (Sweden). She obtained her $\mathrm{PhD}$ in Computer Science from the University of Southampton (UK) in 1999. To date she has published more than 230 fully refereed publications, including 58 fully refereed journal papers, and three books (one edited and two as sole author). Recently she has been ranked amongst the top $2 \%$ best scientists in the world, based upon citations to her career. Currently she is editorial board member of Information and Software Technology.

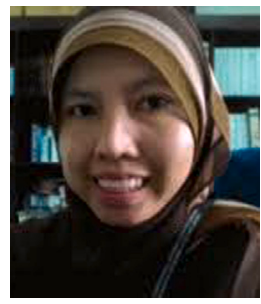

Former editorial board member of IEEE Transactions on Software Engineering, the Software Quality Journal, and Empirical Software Engineering Journal. Program Committee membership of $200+$ events, representing editions of $45+$ International \& regional conferences, $25+$ international \& regional workshops, and others (e.g. summer schools). The core of her research is applied and falls mostly within Empirical Software Engineering, and relating specifically to: i) the use of statistical and machine learning techniques for dementia prognosis and for prediction in a number of areas such as value-based decision making, software development effort, productivity, software quality, and team climate in Agile software development; ii) Methodological aspects in Software Engineering relating to Systematic Literature Reviews (when and how to update reviews); iii) Best strategies for Agile team formation (aiming at higher productivity, quality and climate); human factors in Software Engineering; and iv) use of Grounded theory to understand industrial practices.

Norsaremah Salleh is associate Professor of Computer Science Department, International Islamic University Malaysia (IIUM). She hold the BSc (Hons) in Information Technology from Universiti Utara Malaysia, MSc in Computer Science (Real Time Software Engineering) from Universiti Teknologi Malaysia, and $\mathrm{PhD}$ in Computer Science from the University of Auckland, New Zealand.

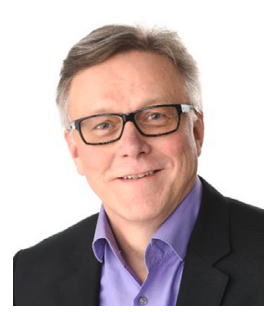

Markku Oivo is professor and head of the M3S research unit at the University of Oulu, Finland. He had visiting positions at the University of Maryland (1990-91), Schlumberger Ltd. (Paris 1994-95), Fraunhofer IESE (19992000), University of Bolzano (2014-15), and Universidad Politecnica de Madrid (2015). 